\title{
$N$-acetylglucosamine 2-Epimerase from Pedobacter heparinus: First Experimental Evidence of a Deprotonation/Reprotonation Mechanism
}

\author{
Su-Yan Wang ${ }^{1}$, Pedro Laborda ${ }^{1}$, Ai-Min Lu ${ }^{2}$, Xu-Chu Duan ${ }^{1}$, Hong-Yu Ma ${ }^{3}$, Li Liu ${ }^{1, *}$ \\ and Josef Voglmeir ${ }^{1, *}$ \\ 1 Glycomics and Glycan Bioengineering Research Center (GGBRC), College of Food Science and Technology, \\ Nanjing Agricultural University, Nanjing 210095, China; 2014208001@njau.edu.cn (S.-Y.W.); \\ pedro.laborda@njau.edu.cn (P.L.); 2012208008@njau.edu.cn (X.-C.D.) \\ 2 College of Sciences, Nanjing Agricultural University, Nanjing 210095, China; luaimin@njau.edu.cn \\ 3 Department of Plant Pathology, Nanjing Agricultural University, Nanjing 210095, China; \\ mahongyu@njau.edu.cn \\ * Correspondence: lichen.liu@njau.edu.cn (L.L.); josef.voglmeir@njau.edu.cn (J.V.); \\ Tel: +86-25-8439-9553 (L.L. \& J.V.)
}

Academic Editors: Jose M. Palomo and Cesar Mateo

Received: 26 November 2016; Accepted: 12 December 2016; Published: 17 December 2016

\begin{abstract}
The control of cellular N-acetylmannosamine (ManNAc) levels has been postulated to be an effective way to modulate the decoration of cell surfaces with sialic acid. $N$-acetylglucosamine 2-epimerase catalyzes the interconversion of $N$-acetylglucosamine (GlcNAc) and ManNAc. Herein, we describe the cloning, expression, purification and biochemical characterization of an unstudied $\mathrm{N}$-acetylglucosamine 2-epimerase from Pedobacter heparinus (PhGn2E). To further characterize the enzyme, several $\mathrm{N}$-acylated glucosamine derivatives were chemically synthesized, and subsequently used to test the substrate specificity of PhGn2E. Furthermore, NMR studies of deuterium/hydrogen exchange at the anomeric hydroxy group and C-2 positions of the substrate in the reaction mixture confirmed for the first time the postulated epimerization reaction via ring-opening/enolate formation. Site-directed mutagenesis of key residues in the active site showed that Arg63 and Glu314 are directly involved in proton abstraction and re-incorporation onto the substrate. As all mechanistically relevant active site residues also occur in all mammalian isoforms, PhGn2E can serve as a model $\mathrm{N}$-acetylglucosamine 2-epimerase for further elucidation of the active site mechanism in these enzymes.
\end{abstract}

Keywords: sialic acid metabolism; $N$-acetylglucosamine 2-epimerase; deprotonation/reprotonation mechanism; Neu5Ac analogues; synthesis of sialic acid analogues

\section{Introduction}

Sialic acids are naturally occurring carbohydrate derivatives of neuraminic acid and 2-keto-3-deoxy-D-glycero-D-galactonononic acid [1]. Sialic acids are generally found at the termini of protein and lipid linked glycoconjugates on cell surfaces, and have been demonstrated to play a crucial role in cell recognition, modulation of cell receptors, tumor metastasis and pathogen binding [2-6]. In recent years, remarkable efforts have been undertaken towards further understanding the biosynthesis and regulation of the sialic acid metabolism on a cellular level [7,8]. ManNAc has been postulated to be the main sialic acid precursor. The biosynthesis of $N$-acetylneuraminic acid (Neu5Ac) from ManNAc can be either achieved via phosphorylation by ManNAc 6-kinase and aldol addition of phosphoenolpyruvate (PEP) by sialic acid 9-P-synthase following an enzymatic dephosphorylation (Scheme 1, route A) $[9,10]$, or the direct (reversible) aldol addition by sialic acid 
aldolase (Scheme 1, route B) [11]. The resulting sialic acid is then converted into its activated precursor form $\mathrm{CMP}-\mathrm{N}$-acetylneuraminic acid and transported into the Golgi apparatus, where it is ultimately utilized by various sialyltransferases to decorate oligosaccharide chains [12]. As ManNAc is the sole carbohydrate precursor in the biosynthesis of $\mathrm{N}$-acetylneuraminic acid, a better understanding of the ManNAc biosynthesis will therefore also lead to a more profound knowledge of the sialic acid metabolism in cells.

The biosynthesis of ManNAc in mammals is regulated in two different ways (Scheme 1, top): in the liver, UDP-GlcNAc is epimerized to UDP-ManNAc and subsequently hydrolyzed to ManNAc by the bifunctional enzyme UDP-GlcNAc 2-epimerase [13]. Alternatively, GlcNAc can be directly epimerized to ManNAc by GlcNAc 2-epimerase (mainly in kidneys) [14,15]. Several GlcNAc 2-epimerases of either mammalian or bacterial origin have been functionally characterized so far [15-22]. The major difference between the two types of enzymes is that mammalian isoforms require nucleotides as co-factor, whereas bacterial isoforms may show enhanced activities in the presence of nucleotides but have no co-factor requirements $[20,23]$.

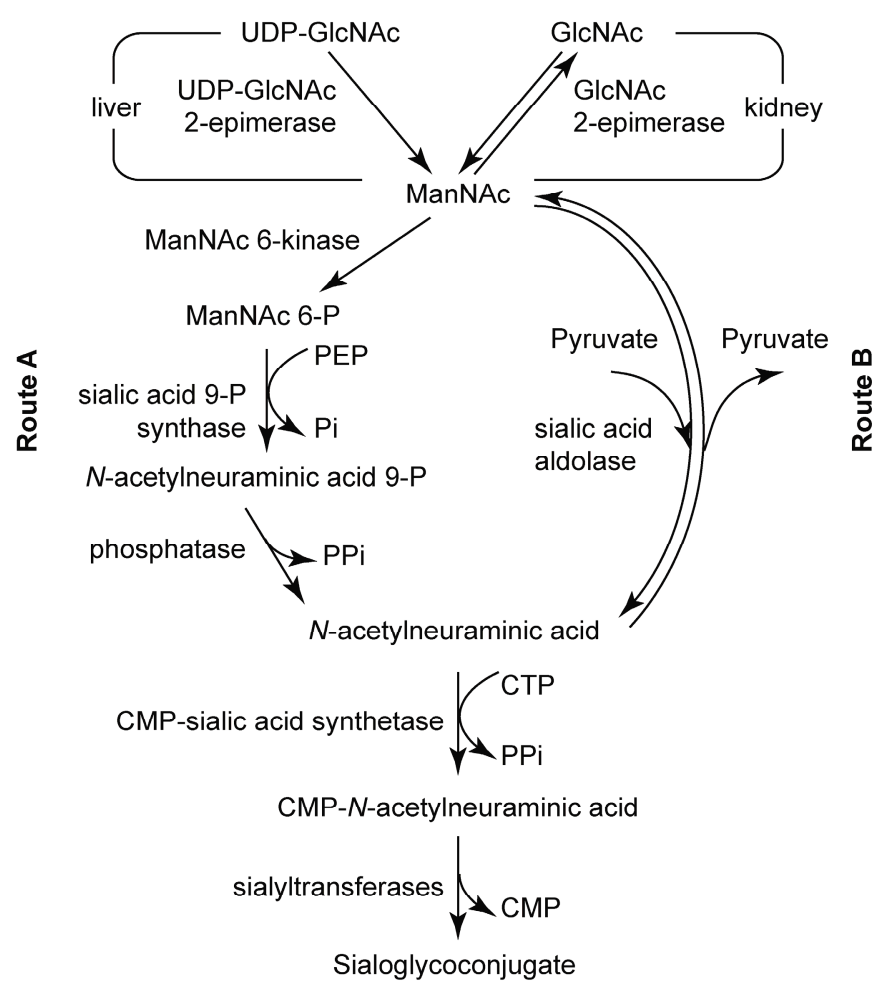

Scheme 1. Sialic acid biosynthesis.

GlcNAc 2-epimerases are interesting targets for the development of novel inhibitors of sialic acid biosynthesis. However, the main limitation in the development of effective inhibitors is the lack of information on the epimerization mechanism. Despite speculations by Samuel and Tanner that the mechanism of the closely related enzyme UDP-GlcNAc 2-epimerase is based on deprotonation/reprotonation or on elimination [24], no experimental studies have yet been reported to support either of these theories. Crystallographic studies of mammalian (porcine) and bacterial (Anabaena sp.) GlcNAc 2-epimerase apoproteins have indicated the involvement of various amino acid residues in the reaction mechanism $[18,25]$. Therefore, we performed a mutational analysis to further elucidate the role of these amino acids. Furthermore, we describe the purification and biochemical and mechanistic characterization of a novel GlcNAc 2-epimerase originating from the soil bacterium Pedobacter heparinus, confirming for the first time the postulated deprotonation/reprotonation mechanism for this class of enzymes. 


\section{Results}

\subsection{Cloning and Homology Analysis of PhGn2E Gene}

A gene canditate encoding a putative GlcNAc 2-epimerase was selected from the genome of Pedobacter heparinus. The full length open reading frame (ORF) of the gene was successfully cloned and consisted of 1212 base pairs. A homology search revealed that PhGn2E is closely related to the GlcNAc 2-epimerase from mammals showing 35\% identity to the human, bovine, murine and rat isoforms and $34 \%$ to the porcine isoform (Supplementary Figure S1). Among bacterial GlcNAc 2-epimerases, PhGn2E showed high amino acid sequence similarity with characterized isoforms from Bacteroides ovatus (48\%) and Anabaena sp. (37\%).

\subsection{Protein Expression and Purification}

The putative gene product was successfully expressed in soluble form. The recombinant protein containing an additional hexa-histidine tag at the $C$-terminus was purified to homogeneity as judged by SDS-PAGE (Figure 1A). The purified sample migrated as a single protein band with a molecular weight between $40 \mathrm{kDa}$ and $50 \mathrm{kDa}$, which is in good agreement with the calculated mass of $47.1 \mathrm{kDa}$ (including the $1.3 \mathrm{kDa}$ hexa-histidine tag). The identity of the purified protein band was confirmed using tryptic peptide mass fingerprinting by matching the obtained MALDI-TOF MS data with the Mascot software database (Supplementary Table S1). The protein concentration of the purified PhGn2E was determined to be $2.73 \pm 0.05 \mathrm{mg} / \mathrm{mL}$ and relative enzymatic activity was determined to be $3.59 \mathrm{U} / \mathrm{mg}(1 \mathrm{U}$ is defined as the amount of enzyme which generates $1 \mu \mathrm{mol}$ of $\mathrm{N}$-acetylmannosamine in $1 \mathrm{~min}$ at $37^{\circ} \mathrm{C}$ ).

A

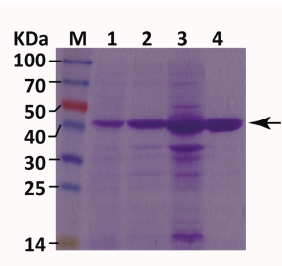

C

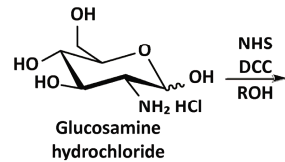

B
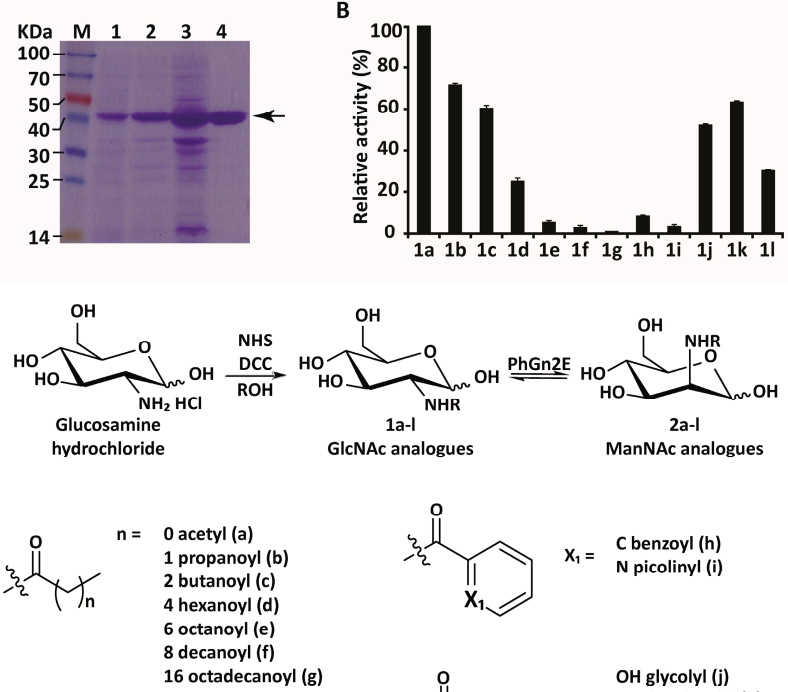

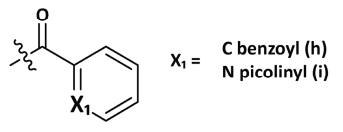

$\mathrm{X}_{2} \quad \mathrm{X}_{2}=\begin{aligned} & \mathrm{OH} \text { glycolyl (j) } \\ & \mathrm{SH} \text { thioglycolyl (k) } \\ & \mathrm{N}_{3} \text { azidoacetyl (I) }\end{aligned}$

Figure 1. (A): SDS-PAGE analysis of heterologous expressed PhGn2E in E. coli. M: protein marker; 1: cell pellets before induction; 2: cell pellets after induction; 3: supernatant of cell lysate; 4: Ni-NTA purified enzyme; (B): Substrate promiscuity of PhGn2E. PhGn2E showed activity towards $N$-acetylglucosamine (1a); N-propanoylglucosamine (1b); N-butanoylglucosamine (1c); $N$-hexanoylglucosamine (1d); N-octanoylglucosamine (1e); N-decanoylglucosamine (1f); N-benzoylglucosamine (1h); $N$-picolinylglucosamine (1i); $N$-glycolylglucosamine (1j); $N$-thioglycolylglucosamine (1k) and $\mathrm{N}$-azidoacetylglucosamine (11). PhGn2E showed no activity towards $\mathrm{N}$-octadecanoylglucosamine (1g). Data are presented as mean values \pm standard deviation of three independent experiments; (C): Reaction scheme of the synthesis of GlcNAc analogs by treatment with NHS (N-hydroxysuccinimide), DCC (Dicyclohexylcarbodiimide) and the corresponding acid using glucosamine as the starting material and epimerization to ManNAc analogs using PhGn2E yielding ManNAc analogues (2a-2l). 


\subsection{Substrate Specificity}

The screening of various chemically synthesized substrates (Figure 1B, Supplementary Figures S2 and S3) revealed that recombinant PhGn2E was able to catalyze the epimerization reaction when GlcNAc derivatives bearing small $N$-acyl groups such as $N$-propanoylglucosamine, $\mathrm{N}$-butanoylglucosamine, $\mathrm{N}$-hexanoylglucosamine, $\mathrm{N}$-octanoylglucosamine, $\mathrm{N}$-glycolylglucosamine or $\mathrm{N}$-thioglycolyl- glucosamine (Figure $1 \mathrm{C}$, compounds $\mathbf{1 b}, \mathbf{1} \mathbf{c}, \mathbf{1} \mathbf{d}, \mathbf{1 e}, \mathbf{1} \mathbf{j}$ and $\mathbf{1 k}$, respectively). However, the activity decreased significantly when substrates with bulkier modifications such as $\mathrm{N}$-decanoylglucosamine and $\mathrm{N}$-octadecanoylglucosamine were used (Figure $1 \mathrm{C}$, compounds $\mathbf{1 f}$ and $1 \mathrm{~g}$, respectively). PhGn2E was also able to catalyze the epimerization reaction of GlcNAc derivatives bearing a hydroxyl $(\mathbf{1 j})$, a thiol $(\mathbf{1 k})$ or azido ( $N$-azidoacetylglucosamine, $\mathbf{1 1})$ moiety in the $N$-linked substituent. Low, but detectable activities towards GlcNAc derivatives containing aromatic side-chains (N-benzonylglucosamine, $\mathbf{1 h}$ and $\mathrm{N}$-picolinylglucosamine, $\mathbf{1 i}$ ) were also observed. Both NMR analysis and platereader based activity assays indicated that PhGn2E showed no activity towards glucosamine, $\alpha$-methyl GlcNAc, $\beta$-methyl GlcNAc and UDP-GlcNAc. Furthermore, all the synthesized GlcNAc derivatives except $1 \mathrm{~g}$ could be successfully converted into sialic acid analogues and linked onto X-gal following the synthetic route shown in Figure 2 and Supplementary Figures S4-S6.

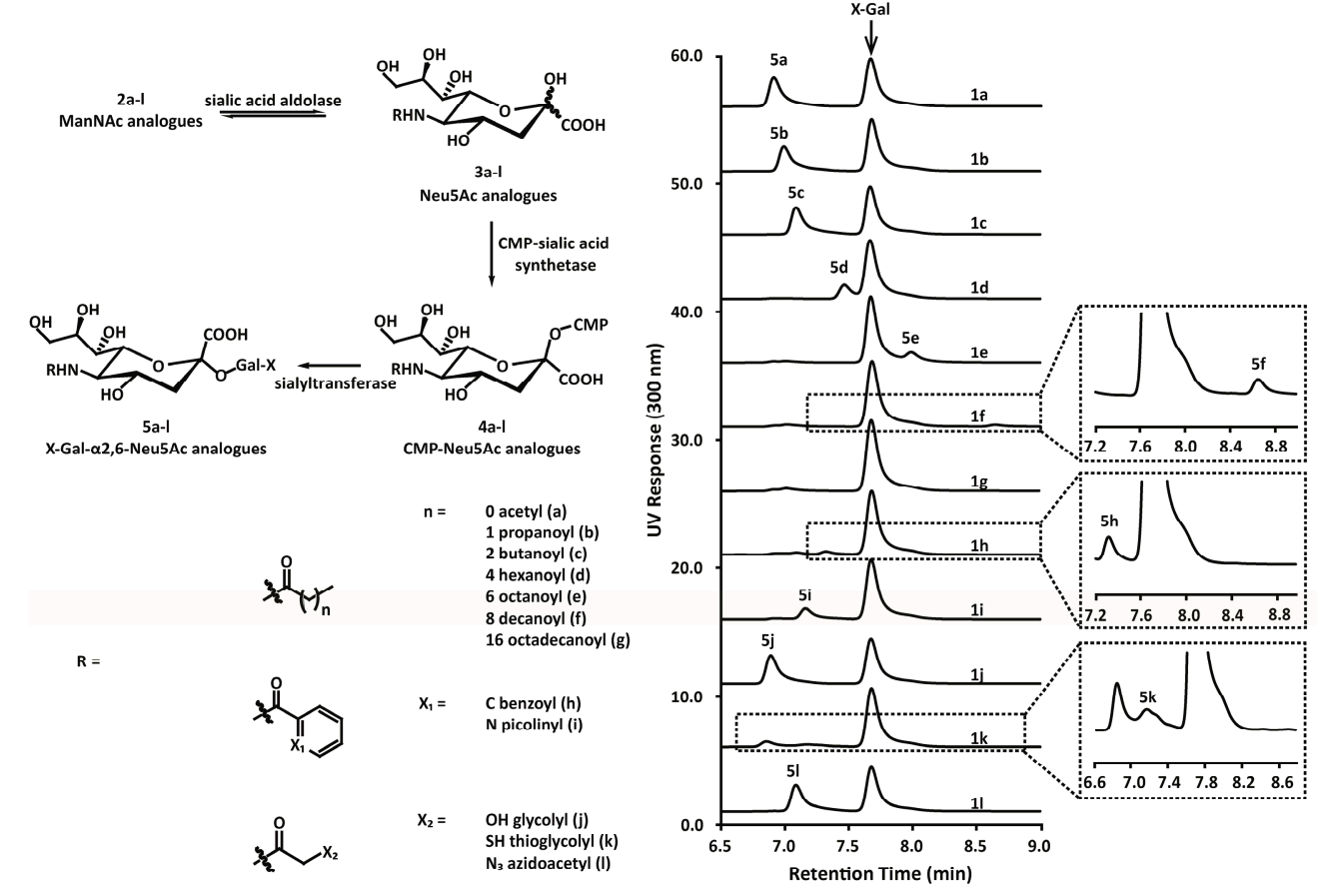

Figure 2. Reaction scheme of the synthesis route of $\mathrm{X}$-gal sialosides. 2a-l was achieved by PhGn2E using $\mathbf{1 a}-\mathbf{1}$ as substrates. The resulting $X$-gal sialosides $(\mathbf{5 a}, \mathbf{5 b}, \mathbf{5 c}, \mathbf{5 d}, \mathbf{5 e}, \mathbf{5 f}, \mathbf{5 h}, \mathbf{5 i}$, $5 \mathbf{j}, 5 \mathbf{k}$ and $5 \mathbf{l})$ were synthesized by a four-enzyme reaction starting with $N$-acetylglucosamine (1a); N-propanoylglucosamine (1b); N-butanoyl- glucosamine (1c); N-hexanoylglucosamine (1d); N-octanoylglucosamine (1e); N-decanoylglucosamine (1f); $N$-benzonylglucosamine (1h);

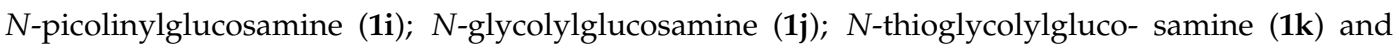
$\mathrm{N}$-azidoacetylglucosamine (11) as initial substrates with relative conversion rates of $37 \%, 33 \%, 37 \%$, $15 \%, 16 \%, 2.3 \%, 3.1 \%, 13 \%, 39 \%, 3.2 \%$, and $38 \%$, respectively. No yield from $1 \mathrm{~g}$ was observed to obtain $5 \mathrm{~g}$.

\subsection{Biochemical Characterization}

PhGn2E activity was tested in a coupled enzymatic assay, by monitoring the $\mathrm{N}$-acyl-D-mannosamine dehydrogenase-catalyzed reduction of $\mathrm{NAD}^{+}$in the presence of ManNAc 
to $\mathrm{NADH}$, which can be followed in a plate reader-based photometric assay. The optimum reaction temperature was determined to be $37^{\circ} \mathrm{C}$ (Figure 3A). Above $37^{\circ} \mathrm{C}$, enzymatic activity rapidly decreased with increasing temperatures. The enzyme showed reasonable thermal stability when incubated at $45^{\circ} \mathrm{C}$ or below for $2 \mathrm{~h}$, and showed no loss of activity when incubated at $30^{\circ} \mathrm{C}$ or below for $24 \mathrm{~h}$ (Supplementary Figure S7). The enzyme showed good activity in a relatively broad $\mathrm{pH}$ range from $\mathrm{pH} 7.0$ to $\mathrm{pH} 10.0$, but decreased rapidly below and above this range (Figure 3B). Considering that small proportions of GlcNAc may also epimerize into ManNAc under stronger basic conditions, $\mathrm{pH} 8.0$ was chosen for further experiments. The addition of $\mathrm{Ca}^{2+}, \mathrm{Mg}^{2+}, \mathrm{Mn}^{2+}, \mathrm{Zn}^{2+}, \mathrm{Cu}^{2+}, \mathrm{Co}^{2+}$ or EDTA had no effect on the enzyme's activity, while $\mathrm{Fe}^{2+}, \mathrm{Fe}^{3+}$ and $\mathrm{Al}^{3+}$ slightly inhibited and $\mathrm{Ni}^{2+}$ slightly increased the activity of PhGn2E (Figure 3C). Denaturants (urea and 2-mercarptoethanol) and detergents (SDS and Triton X-100) showed significant inhibitory effects on the enzymatic activity (Supplementary Figure S8). The effect of nucleotides on PhGn2E was also examined (Supplementary Figure S9A), showing that ATP but no other nucleotide enhanced the activity of PhGn2E. To evaluate the influence of adenine-derived nucleotides on PhGn2E activity, the inhibition of AMP, ADP and ATP was further studied in a dose-dependent manner (Supplementary Figure S9B). Whereas AMP and ADP had no significant effect at any measured concentration, the addition of $100 \mu \mathrm{M}$ of ATP resulted almost in a doubling of enzymatic activity and the addition of $1 \mathrm{mM}$ of ATP led to a 4-fold increase. The $K_{\mathrm{M}}$ value of PhGn2E was $82 \pm 7 \mathrm{mM}$ for GlcNAc, the $\mathrm{V}_{\max }$ value $197 \pm 4 \mu \mathrm{M} \cdot \mathrm{min}^{-1}$ and the $\mathrm{k}_{\text {cat }}$ value $340 \pm 3 \mathrm{~min}^{-1}$. A mutational analysis of PhGn2E was performed in order to confirm the residues which are involved in the epimerization reaction. Arg63, His244, Glu314 and His378 were chosen as the target amino acids for this study. The activities of PhGn2E mutants H244A and H378A were $13.6 \% \pm 1.0 \%$ and $6.9 \% \pm 0.9 \%$ of that of the wild type enzyme, whereas the mutants $\mathrm{R} 63 \mathrm{~A}$ and E314A showed no epimerase activity (Figure 3D).
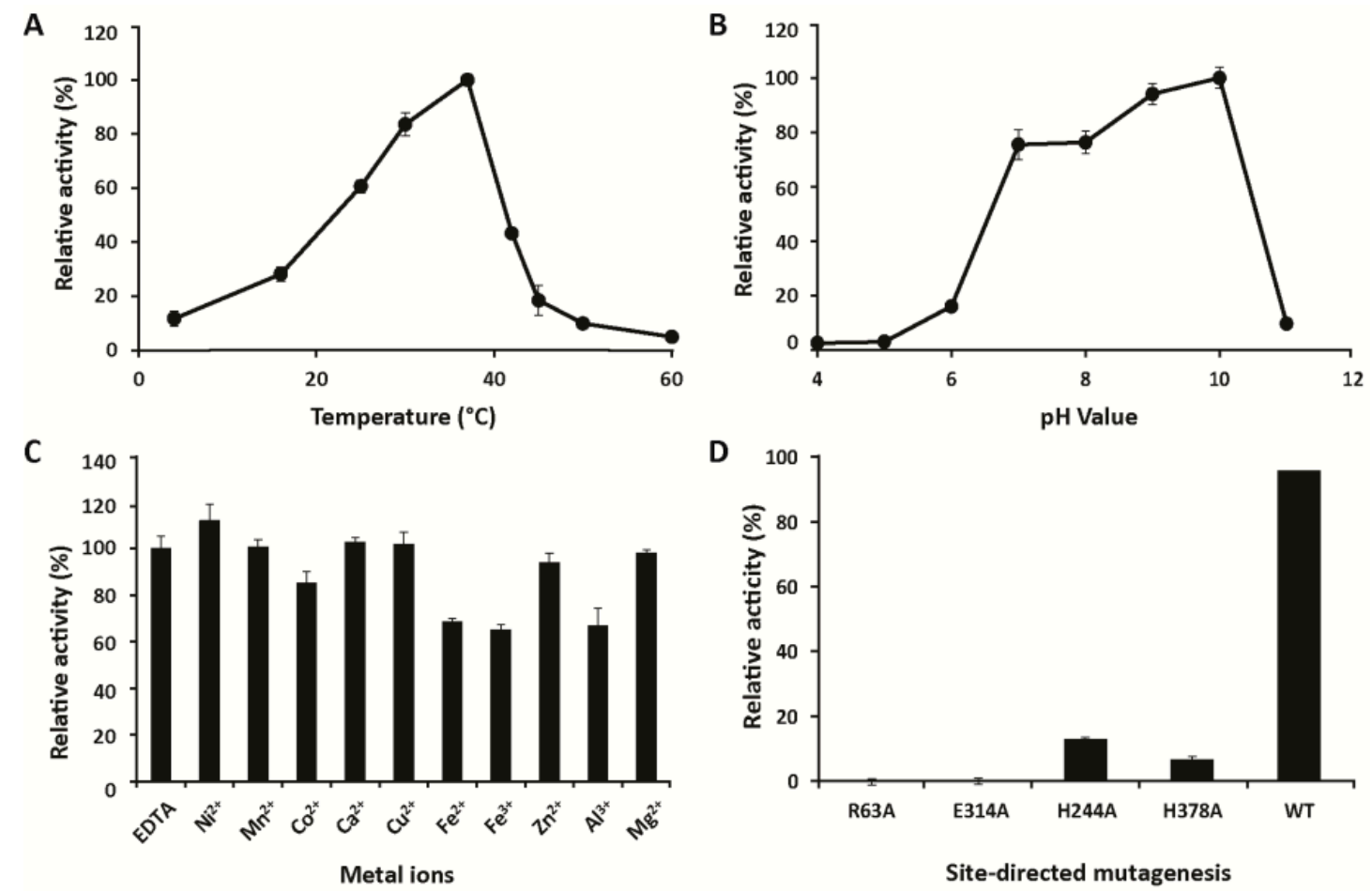

Figure 3. Biochemical characterization of PhGn2E. (A): Temperature dependency of recombinant PhGn2E; (B): pH-dependency of recombinant PhGn2E; (C): Impact of metal ions on the enzymatic activity of PhGn2E; (D): Activity study of PhGn2E active site mutants. Negative controls contained heat-inactivated wild-type (WT) PhGn2E. Data are presented as mean values \pm standard deviation of three independent experiments. 


\subsection{Hydrogen/Deuterium Exchange Analysis}

${ }^{1} \mathrm{H}_{-},{ }^{13} \mathrm{C}-$-, TOCSY-, and HSQC-NMR spectra of GlcNAc and ManNAc provided by the BMRB repository [26] were used for the accurate assignment of the obtained NMR signals. After the epimerization reaction in deuterated water $\left(\mathrm{D}_{2} \mathrm{O}\right)$, the acquired ${ }^{1} \mathrm{H}-\mathrm{NMR}$ spectrum revealed the disappearance of the signal corresponding to the C-2 linked proton of ManNAc (ManNAc H2, 4.5-4.3 ppm) indicating a hydrogen/deuterium exchange at this position (Figure 4A-D). Similarly, the relative integral value of the multiplet between 4.1 and $3.3 \mathrm{ppm}$ (protons linked to C-2, C-3, C-4, C-5 and C-6) of the reaction mixture showed a ratio of 5:1 with respect to the anomeric proton signals (4 signals: 5.19, 5.12, 5.02 and $4.71 \mathrm{ppm}$ ) instead of the expected ration of $6: 1$, which is in agreement with hydrogen/deuterium exchange at C-2 of GlcNAc (GlcNAc H2, 4.1-3.3 ppm) (Figure 4D). On the other hand, a deuterium/hydrogen exchange could be also observed in the anomeric alcohol of GlcNAc after the addition of heat-inactivated PhGn2E. However, integrating the relative areas of the signals corresponding to the anomeric proton of the $\beta$ anomer $(\beta \mathrm{H} 1,6.44 \mathrm{ppm})$ and the anomeric alcohol of the $\beta$ anomer ( $\beta \mathrm{OH} 1,4.93 \mathrm{ppm}$ ) showed $6 \%$ of deuterium/hydrogen exchange when GlcNAc was incubated for 15 min using $\mathrm{D}_{2} \mathrm{O}$ as the solvent in the presence of the inactivated epimerase (Figure 5A-C); while the almost complete disappearance of the signal corresponding to the anomeric alcohol was observed when active PhGn2E was added (Figure 5D).

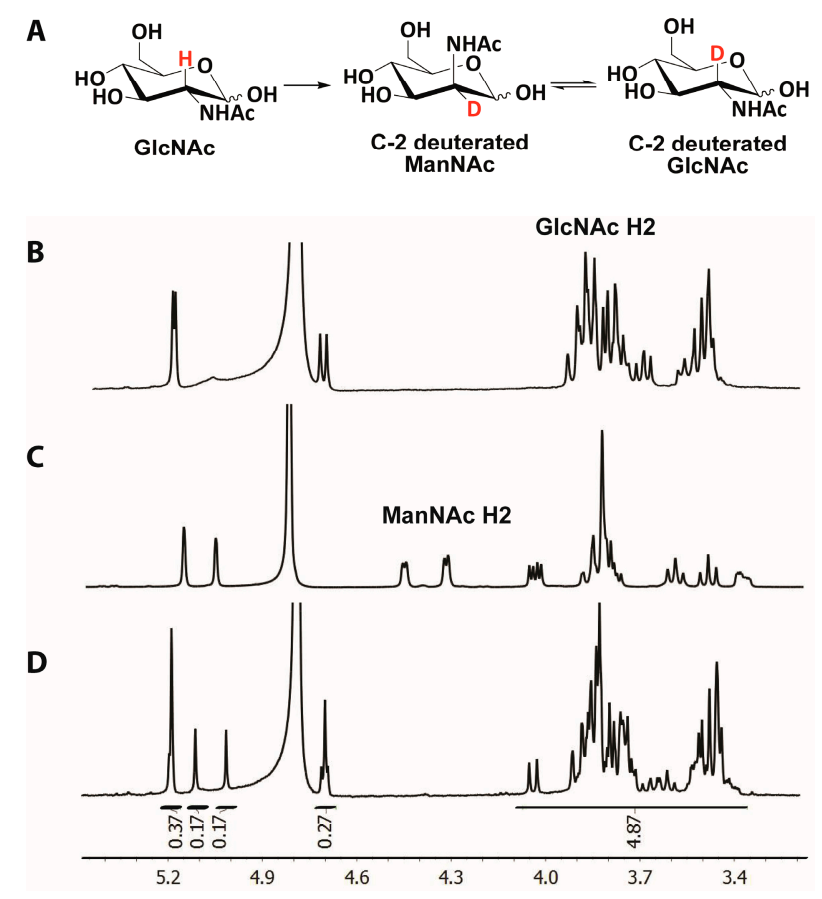

Figure 4. (A): Reaction scheme of PhGn2E-catalyzed deuterium substitution at the C-2 position of GlcNAc allowing the formation C-2 deuterated ManNAc; $(\mathbf{B}):{ }^{1} \mathrm{H}-\mathrm{NMR}$ spectrum of GlcNAc in $\mathrm{D}_{2} \mathrm{O}$; (C): ${ }^{1} \mathrm{H}-\mathrm{NMR}$ spectrum of ManNAc in $\mathrm{D}_{2} \mathrm{O}$; (D): ${ }^{1} \mathrm{H}-\mathrm{NMR}$ spectrum of GlcNAc after incubation with $\mathrm{PhGn} 2 \mathrm{E}$ in $\mathrm{D}_{2} \mathrm{O}$. 
A
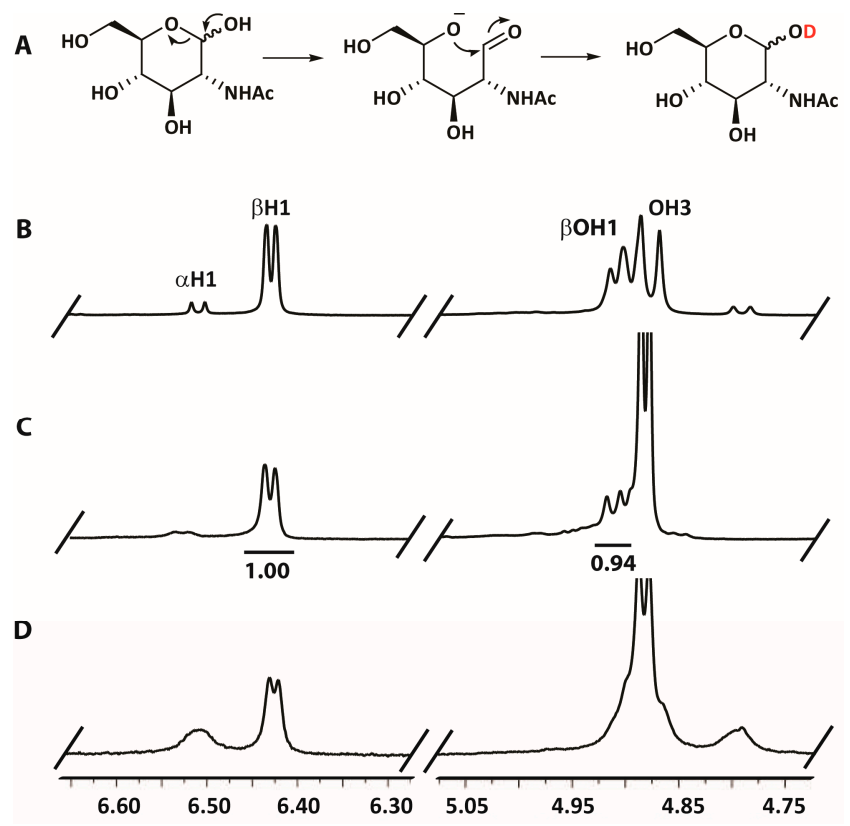

Figure 5. (A): Reaction scheme of the hydrogen/deuterium exchange on the anomeric alcohol of GlcNAc. The pyranose ring opening involves the formation of a double bond at the anomeric carbon to form an intermediate aldehyde. The C-5 oxygen of the intermediate then attacks the anomeric carbon, closing the ring again. The anomeric oxygen is deuterated by the solvent; (B): ${ }^{1} \mathrm{H}-\mathrm{NMR}$ spectrum of GlcNAc in DMSO- $d_{6} ;(\mathbf{C}):{ }^{1} \mathrm{H}-\mathrm{NMR}$ spectrum of the reaction mixture containing $20 \mathrm{mM}$ GlcNAc and inactivated $\mathrm{PhGn} 2 \mathrm{E}$ in $\mathrm{D}_{2} \mathrm{O}$ after $15 \mathrm{~min}$ incubation at $37^{\circ} \mathrm{C}$ (spectrum was recorded in DMSO- $d_{6}$ ); (D): ${ }^{1} \mathrm{H}-\mathrm{NMR}$ spectrum of the reaction mixture containing $20 \mathrm{mM}$ GlcNAc and PhGn2E in $\mathrm{D}_{2} \mathrm{O}$ after $15 \mathrm{~min}$ incubation at $37^{\circ} \mathrm{C}$ (spectrum was recorded in DMSO- $d_{6}$ ).

\section{Discussion}

\subsection{Characterization}

The recombinant form of PhGn2E could be successfully purified and was observed as a single protein band of expected molecular weight on SDS-PAGE. The enzyme showed good expression levels and had, after purification, a high specific activity of $3.59 \mathrm{U} / \mathrm{mg}$. Furthermore, microplate reader-, HPLC-, and NMR-based methods unambiguously demonstrated the enzymatic epimerization activity of PhGn2E.

Although PhGn2E showed no activity at temperatures of $50{ }^{\circ} \mathrm{C}$ and above, the enzyme showed reasonable stability when incubated at $37{ }^{\circ} \mathrm{C}$ for up to $12 \mathrm{~h}$. This makes $\mathrm{PhGn} 2 \mathrm{E}$ potentially suitable for biotechnological applications at ambient temperatures with longer incubation times, such as continuous biotransformations. The optimum temperature of PhGn2E was determined to be $37^{\circ} \mathrm{C}$. This value is comparable with the reported temperature optimum for the cyanobacterium Synechocystis sp. PCC 6803 [27], whereas B. ovatus, porcine, and A. variabilis isoforms showed higher temperature optima ( 45 to $60{ }^{\circ} \mathrm{C}$, respectively) $[19,28,29]$. The $\mathrm{pH}$ optimum of $\mathrm{PhGn} 2 \mathrm{E}$ lies slightly higher than other characterized epimerases, which were reported to lie between 6.8-8.5 for the porcine, Anabaena sp., B. ovatus, and Synechocystis sp. PCC6803 homologues $[22,23,27,29]$. The addition of EDTA or metal ions did not significantly decrease or inhibit PhGn2E activity, which indicates that metal ions are not involved in the catalytic mechanism of the enzyme. Kinetic analysis showed that the measured $K_{\mathrm{M}}$ value of $82 \mathrm{mM}$ was higher compared to other reported $K_{\mathrm{M}}$ values (between 7 and $32 \mathrm{mM})[22,23,27,29,30]$, which might be an advantage for biotransformations performed at high substrate concentrations. 
While several bacterial GlcNAc 2-epimerases show activity in absence of nucleotides, the addition of ATP has been reported to enhance enzymatic activity for some isoforms. For example, the activity of Anabaena sp. epimerase was enhanced in the presence of ATP and the non-hydrolyzable $\gamma$-phosphate analogue 5'-adenylyl imidodiphosphate [23]. It has been demonstrated that the addition of ATP stabilizes the B. ovatus epimerase leading to an increased denaturation temperature and an enhanced $\mathrm{pH}$ activity range [31]. In a similar manner, the activity of PhGn2E also increased significantly in the presence of ATP. While mammalian epimerases can be activated in presence of a wide range of nucleotides such as AMP, ADP, ATP, CTP, GTP or UTP [30], PhGn2E activity remained unchanged in the presence of these nucleotides. Two different theories of how ATP-binding effects the activity of GlcNAc 2-epimerase currently exist; Liao et al. suggested an ATP-binding site in Anabaena sp. GlcNAc 2-epimerase site 151-KDNPKGKYTK-160 (Supplementary Figure S1), and that the residues Lys151 and Lys160 are required for ATP binding [23]. A second hypothesis by Sola-Carvajal et al. suggests that the lysine residues in a different motif located at the $C$-terminus of the analyzed B. ovatus isoform (392-KGGKWKG-398, Supplementary Figure S1) are responsible for ATP binding [31]. This motif was also found in the $C$-terminal region of PhGn2E (369-KGNLFKG-375), and in other functionally described isoforms from Anabaena sp. and mammals (Supplementary Figure S1), suggesting that the lysine residues at the $C$-terminal region may be responsible for the binding of ATP.

\subsection{Chemoenzymatic Synthesis of Mannosamine and Sialic Acid Derivatives}

The synthesis of mannosamine and sialic acid derivatives is one of the main limitations in studying them as potential inhibitors of the sialic acid metabolic pathway [32-37]. In this field, several research groups have reported the synthesis of mannosamine derivatized with $N$-linked aliphatic chains. This is generally achieved by using NHS-activated acids [38,39], or alternatively, can also be achieved by treatment of isobutyl chloroformate with an acid, yielding an amine-reactive anhydride [36,40]. Sampathkumar et al. reported the synthesis of peracetylated ManNAc analogues by treatment with naphthaldehyde for $\mathrm{N}$-activation using ManN hydrochloride as starting material [41]. However, the high price of mannosamine is a major limitation in the synthesis of sialic acid analogues. Incorporating PhGn2E into the synthetic route allows the use of glucosamine-based analogues, which reduces the cost of the synthesis to a fraction of that of the mannosamine-based synthesis.

The mannosamine derivatives obtained from the PhGn2E-catalyzed reaction were used as precursors for the synthesis of Neu5Ac (3a) analogues. These Neu5Ac analogues bearing alternative $N$-linked acyl chains could be synthetized by the sialic acid aldolase-catalyzed addition of pyruvate. Several chemical strategies to generate Neu5Ac derivatives with C-5 modifications have been successfully applied so far, including modification with benzyl- and azido groups [42,43]. A free amino group has been demonstrated to be a suitable nucleophile for protection with Fmoc, Alloc or Boc carbamates [42,43]. Unprotected neuraminic acid had also been used for the addition of trifluoroacetamido, trichloroethoxycarbonyl or 4-O-oxazolidinone groups, replacing the acetyl group [43]. Keppler et al. used a whole cell biotransformation to produce $N$-propanoyl, $N$-butanoyl and $N$-pentanoyl neuraminic acids by fermentation in Madin-Darby canine kidney cells using the corresponding ManNAc derivatives as the starting material [44]. The same strategy was applied by Lundgren et al. to produce a sialic acid derivative from $\mathrm{N}$-butanoylglucosamine in genetically engineered E. coli [45]. The chemoenzymatic synthesis of various sialosides based on mannosamines derivatized with fluoride-, azido- or methoxide groups in a one-pot, three-enzyme approach with recombinant enzymes was later reported by the group of Chen $[38,46]$. The herein characterized $\mathrm{PhGn} 2 \mathrm{E}$ epimerase may also be easily integrated into reported synthetic procedures, which would allow the use of glucosamine derivatives as a starting material.

\subsection{Mechanistic Studies}

Recorded NMR spectra showed hydrogen/deuterium exchange at C-2 in both GlcNAc and ManNAc when the reaction was performed in $\mathrm{D}_{2} \mathrm{O}$. This result can be explained considering that the 
enzyme is catalyzing the deprotonation of GlcNAc at C-2 and, at the same time, the incorporation of deuterium on the opposite face, promoting the epimerization of GlcNAc to C-2 deuterated ManNAc (Figure 4A). Four different mechanisms have been described for epimerization reactions in sugars: the mutarotation mechanism, the transient oxidation-reduction mechanism, the elimination mechanism and the deprotonation/reprotonation mechanism (Supplementary Figure S10) [24]. The mutarotation mechanism is only applicable for epimerization reactions at the anomeric center and can be therefore excluded. As GlcNAc 2-epimerases contain no co-enzymes such as FAD or NAD ${ }^{+}$, a transient oxidation-reduction mechanism, with no observable proton/deuterium exchange in the substrate, can be also excluded as possible mechanism. In both the deprotonation/reprotonation mechanism and the elimination mechanism, two different residues are involved in the proton capture and proton donation steps, allowing hydrogen/deuterium exchange. To discern between the two possible mechanisms, the activity of PhGn2E towards anomeric $O$-substituted GlcNAc derivatives was studied. PhGn2E showed no activity towards methyl $\alpha$-GlcNAc, methyl $\beta$-GlcNAc or UDP-GlcNAc, indicating that the enzyme is not capable of catalyzing the epimerization reaction in closed ring formation. In addition, deuterium exchange on the anomeric alcohol is faster in presence of PhGn2E (Figure 5C,D). According to the described mechanism for UDP-GlcNAc 2-epimerase, an elimination mechanism for the GlcNAc/ManNAc enzymatic epimerization would involve the release and subsequent incorporation of the hydroxyl group [47], which would consequently lead to no hydrogen/deuterium exchange in the anomeric alcohol. Thus, the hydrogen/deuterium exchange is produced via pyranose ring opening and closure (Figure 5A). This result is in agreement with the deprotonation/reprotonation mechanism wherein the ring opening occurs in order to stabilize by enolate intermediate the anion formed in C-2 after the abstraction of the proton (Figure 6), confirming that the catalytic activity of PhGn2E is based on a deprotonation/reprotonation mechanism.

The deprotonation/reprotonation mechanism requires the participation of two proximate amino acid residues in the active site of the epimerase [24]. Itoh et al. obtained the crystal structure of the porcine isoform, and showed that four amino acid residues (Arg60, His248, Glu251 and His382) are close enough to the active center to be potentially important for catalytic function [18]. While the X-ray diffraction of the enzyme was performed in presence of GlcNAc, the resolution of the substrate was not high enough to carry out further crystallographic refinements and, for this reason, the exact residues involved in the proton abstraction/donation steps could not be identified. Lee et al. reported the three-dimensional structure of GlcNAc 2-epimerase from Anabaena sp., and that the substitution of amino acids in the active site using site-directed mutagenesis showed that Arg57, His239, Glu308, His372, are essential for the epimerization reaction [25]. The sequence alignment of PhGn2E, porcine and Anabaena sp. isoforms (Supplementary Figure S1) show high similarities, especially close to the above mentioned amino acids surrounding the active site. In order to identify the two residues involved in the proton capture/donation steps, the activity of PhGn2E mutants was further investigated. Despite the results of Lee et al., which suggest that His244 and H378 should be responsible for the deprotonation/reprotonation mechanism [25], the PhGn2E mutants H244A and H378A could efficiently catalyze the epimerization reaction from GlcNAc to ManNAc. On the other hand, the PhGn2E mutants E314A and R63A were not capable of catalyzing the epimerization reaction indicating that Arg63 and His372 are the residues involved in the proton abstraction/donation steps (Figure 3D). Thus, one of these residues must participate in abstracting the hydrogen linked to C-2 of GlcNAc followed by incorporation of the hydrogen in the same carbon but in the opposite face by the other residue producing the inversion of configuration.

In order to assign the role of each residue, hydrogen/deuterium exchange studies of PhGn2E mutants E314A and R63A were performed. However, no hydrogen/deuterium exchange could be observed using either ManNAc or GlcNAc as initial substrate. Reports on the B. ovatus epimerase indicated that the epimerization reaction from GlcNAc to ManNAc is faster than the epimerization reaction from ManNAc to GlcNAc [22]. The reason for this may be $\mathrm{pKa}$ values of arginine $(\mathrm{pKa} \approx 12.5)$ and glutamic acid $(\mathrm{pKa} \approx 3.1)$ residues, which indicate that a high proportion of protonated arginine 
and deprotonated glutamic acid residues exist at physiological $\mathrm{pH}$ conditions. Based on these preconditions, we can propose that a GlcNAc in open conformation enters in the central cavity between Arg63 and Glu314. Then, Glu314 deprotonates C-2 of GlcNAc while Arg63 incorporates the proton on the same carbon but on the opposite face yielding ManNAc (Figure 6). Due to the reversibility of the mechanism, GlcNAc 2-epimerase can also catalyze the epimerization from ManNAc to GlcNAc through the deprotonation of ManNAc in C-2 by Arg63 followed by the reprotonation by Glu314 to obtain GlcNAc. This makes GlcNAc 2-epimerases unique among deprotonation/reprotonation epimerases which commonly employ residues containing carbonyl, carboxylic acid and ester groups as key amino acids for the reaction [24].

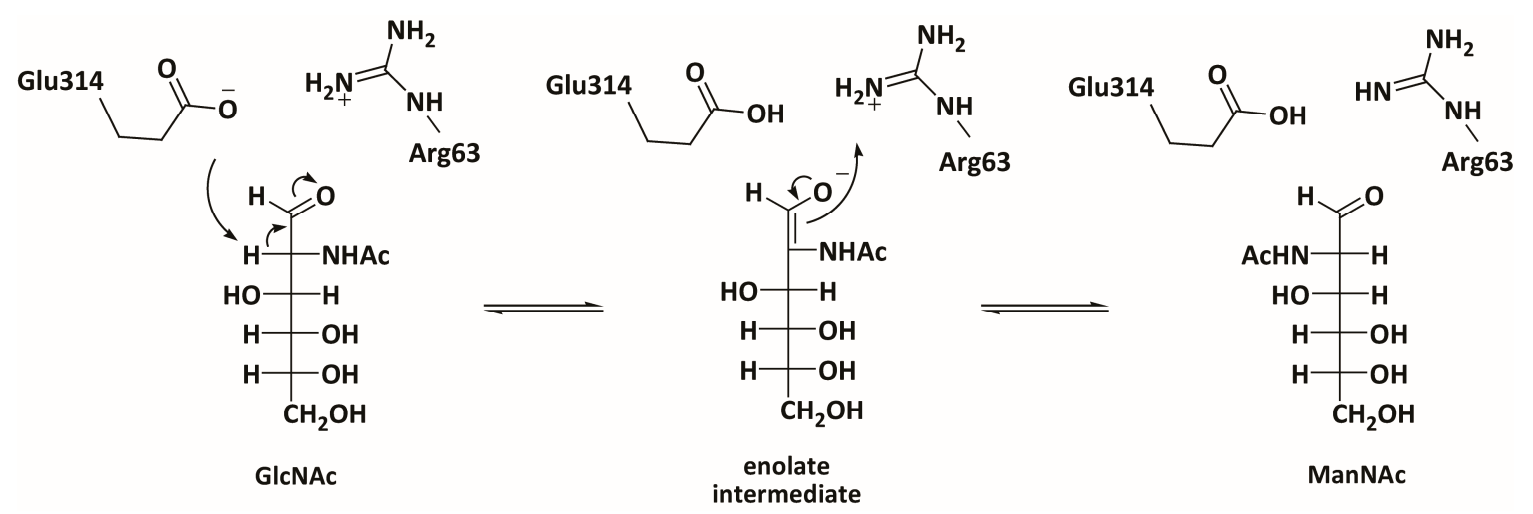

Figure 6. Deprotonation/reprotonation mechanism model of PhGn2E. Glu314 is able to deprotonate and protonate C-2 of GlcNAc while Arg63 is the responsible of the deprotonation and protonation in C-2 of ManNAc.

PhGn2E is highly homologous with mammalian GlcNAc 2-epimerases. Arg63 and Glu314 can be found in the human, bovine, murine, porcine and rat GlcNAc 2-epimerase sequences (Supplementary Figure S1). Furthermore, the crystal structure of porcine GlcNAc 2-epimerase showed that the corresponding arginine and glutamic acid residues are also symmetrically located in the active site (Supplementary Figure S11) [18]. The existence of these homologous residues in the active site of the porcine epimerases, as well as a high similarity in the surrounding residues, is a strong indication that mammalian epimerases also employ a deprotonation/reprotonation mechanism to carry out the C-2 inversion.

\section{Materials and Methods}

\subsection{General}

DNA polymerases were purchased from Takara (Dalian, China); Restriction endonucleases and T4 ligases were obtained from Thermo Fisher Scientific (Shanghai, China); DNA Gel Purification and Plasmid Extraction kits were from Axygen (Beijing, China). Oligonucleotide primers were purchased from GenScript (Nanjing, China). Buffers, salt and other chemicals used in this study were purchased at the highest grade from various suppliers.

\subsection{Bacterial Strains}

Pedobacter heparinus (DSM 2366) was obtained from the German Collection of Microorganisms and Cell Cultures (DSMZ, Darmstadt, Germany). E. coli Mach 1 cells (Life Technologies, Shanghai, China) were used for plasmid amplification and manipulation. E. coli BL21 (DE3) cells (Invitrogen, Shanghai, China) were used for protein expression experiments. 


\subsection{Gene Cloning and Construction of the Expression Vector}

Genomic DNA was isolated from stored lyophilized culture samples of Pedobacter heparinus according to the method described by Mahuku [48]. The oligonucleotide primers for amplifying a putative GlcNAc 2-epimerase were designed based on the P. heparinus genome information provided by the Pathosystems Resource Integration Center (PATRIC) [49] (ph.ggbrc.com) as follows: 5'-GGAATTCCATATGGTTATAGAATATACATTAGAAAAAT-3' (forward primer) and 5'-CCGCTCGAGTTGAGCCGTATAGGAAGCA-3' (reverse primer). Gene amplification was carried out using Primestar HS DNA polymerase based on the manufacturer's instructions. Briefly, the PCR amplification was performed using $35 \mathrm{PCR}$ cycles consisting of denaturation at $95^{\circ} \mathrm{C}$ for $10 \mathrm{~s}$ annealing at $55^{\circ} \mathrm{C}$ for $30 \mathrm{~s}$, and elongation at $72{ }^{\circ} \mathrm{C}$ for $1 \mathrm{~min}$. The PCR fragments were purified on an agarose gel, digested with the restriction endonucleases Nde $I$ and Xho $I$ and subsequently ligated into a pET-30a expression vector, which was pre-digested using the same restriction endonucleases. The ligation mixtures were transformed into E. coli Mach1 T1 competent cells and were selected on Luria-Bertani (LB) agar containing $50 \mu \mathrm{g} / \mathrm{mL}$ kanamycin. Transformants containing the expected plasmid construct were screened by Sanger DNA sequencing (Genscript, Nanjing, China). A clone containing the expected plasmid construct was stored at $-80^{\circ} \mathrm{C}$ and used for further experiments. The extraction of plasmids, endonuclease treatments, ligation, DNA purification and transformation procedures were carried out using standard protocols.

\subsection{Expression and Protein Purification}

E. coli BL 21 (DE3) cells were transformed with the expression plasmid bearing the PhGn2E gene. A single colony was transferred into $5 \mathrm{~mL}$ of LB medium containing $50 \mu \mathrm{g} / \mathrm{mL}$ kanamycin for overnight shaking at $37^{\circ} \mathrm{C}$. The cells were then transferred into $400 \mathrm{~mL} \mathrm{LB}$ medium and shaken ( $\left.200 \mathrm{rpm}\right)$ at $37^{\circ} \mathrm{C}$ until the optical density at $600 \mathrm{~nm}\left(\mathrm{OD}_{600}\right)$ reached a value between 0.5 and 0.8 . Recombinant protein expression was induced by adding $1 \mathrm{mM}$ IPTG to the fermentation broth. After further $24 \mathrm{~h}$ of shaking at $18{ }^{\circ} \mathrm{C}$, cells were harvested by centrifugation $(15 \mathrm{~min}$ at $5000 \mathrm{~g})$, re-suspended in lysis buffer $(50 \mathrm{mM}$ Tris, $100 \mathrm{mM} \mathrm{NaCl}, 1 \%(w / v)$ Triton $\mathrm{X}-100$, adjusted to $\mathrm{pH} 8.0$ with $\mathrm{HCl})$ and disrupted by sonication ( $40 \mathrm{on} /$ off cycles with $20 \mu \mathrm{m}$ probe amplitude for $15 \mathrm{~s}$ ). The supernatant of the cell lysate was collected ( 20 min centrifugation at $14,000 \mathrm{~g}$ ), and loaded onto a $\mathrm{Ni}^{2+}$-nitrilotriacetate agarose affinity column ( $2 \mathrm{~mL}$ bed volume, Qiagen, Shanghai, China) equilibrated with washing buffer ( $50 \mathrm{mM}$ Tris $/ \mathrm{HCl}$, $50 \mathrm{mM} \mathrm{NaCl}, \mathrm{pH} \mathrm{8.0)}$. After washing the column with $30 \mathrm{~mL}$ of washing buffer, the bound target protein was then eluted in $1 \mathrm{~mL}$ fractions of elution buffer $(50 \mathrm{mM}$ Tris $/ \mathrm{HCl}, 50 \mathrm{mM} \mathrm{NaCl}, 500 \mathrm{mM}$ imidazole, $\mathrm{pH}$ 8.0). The progress of protein expression, cell lysis and protein purification was analyzed by SDS-polyacrylamide gel electrophoresis (SDS-PAGE) and visualized using Coomassie brilliant blue G-250. Elution fractions showing the highest purity were pooled and stored in $30 \%$ glycerol $(w / v)$ at $-80^{\circ} \mathrm{C}$ for further experiments. The protein concentration of this pool was measured using a Bradford protein quantification kit (Sangon Biotech, Shanghai, China). Furthermore, Coomassie-stained gels of purified proteins were subject to in-gel tryptic digest and subsequent MALDI-TOF mass spectrometric analysis (Bruker Ultraflex Extreme, Bremen, Germany).

\subsection{Enzymatic Assay}

PhGn2E activity was detected based on the method described by Sola-Carvajal et al. [22] with slight modifications. In general, $10 \mu \mathrm{L}$ assays containing $400 \mathrm{mM}$ of GlcNAc and $0.58 \mu \mathrm{M}$ of PhGn2E in citrate/phosphate buffer $(50 \mathrm{mM}, \mathrm{pH} 8.0)$ and were incubated at $37^{\circ} \mathrm{C}$ for $5 \mathrm{~min}$. The epimerase activity was quenched by adding $70 \mu \mathrm{L}$ of cold methanol and the protein was denatured by storing the samples for $2 \mathrm{~h}$ at $-80^{\circ} \mathrm{C}$. After solvent evaporation, $80 \mu \mathrm{L}$ of deionized $\mathrm{H}_{2} \mathrm{O}$ were added to the samples. The formation of ManNAc was analyzed using $3.4 \mu \mathrm{M}$ of commercial $N$-acyl-D-mannosamine dehydrogenase (Qlyco, Nanjing, China) and $\mathrm{NAD}^{+}(2 \mathrm{mM})$ as a co-factor in a continuous platereader assay at $37{ }^{\circ} \mathrm{C}$ (Thermo Multiscan FC, Shanghai, China). An increase in absorbance at $340 \mathrm{~nm}$ 
resulted from the reduction of $\mathrm{NAD}^{+}$to $\mathrm{NADH}$ when ManNAc was enzymatically oxidized to the corresponding lactone.

\subsection{Biochemical Characterization}

The temperature optimum of PhGn2E was determined by incubating reaction mixtures at various temperatures between $4{ }^{\circ} \mathrm{C}$ to $70{ }^{\circ} \mathrm{C}$ and the generation of ManNAc was subsequently determined with the assay conditions described above. The $\mathrm{pH}$ optimum was investigated using a series of citric acid/phosphate buffers $(50 \mathrm{mM})$ ranging from $\mathrm{pH} 4.0$ to $\mathrm{pH} 10.5$. The thermal stability of PhGn2E was examined by incubating the enzyme at temperatures between $22{ }^{\circ} \mathrm{C}$ and $52{ }^{\circ} \mathrm{C}$ for various durations. Negative controls were prepared without the presence of enzyme. To evaluate the effect of metal ions on the activity of $\mathrm{PhGn} 2 \mathrm{E}$, epimerization reactions were performed in the presence of either $1 \mathrm{mM} \mathrm{Ca}^{2+}, \mathrm{Mg}^{2+}, \mathrm{Mn}^{2+}, \mathrm{Zn}^{2+}, \mathrm{Cu}^{2+}, \mathrm{Co}^{2+}, \mathrm{Fe}^{2+}, \mathrm{Fe}^{3+}, \mathrm{Ni}^{2+}, \mathrm{Al}^{3+}$ (all in their chloride form) or $1 \mathrm{mM}$ ethylenediaminetetraacetate (EDTA).

The effect of several denaturants and detergents on PhGn2E was assessed for 2-mercaptoethanol $(10 \mathrm{mM}, 50 \mathrm{mM}, 100 \mathrm{mM})$, urea $(0.5 \mathrm{M}, 1 \mathrm{M}, 2 \mathrm{M})$, Triton-X $100(0.1 \%, 0.5 \%, 1 \%)$ and SDS $(0.1 \%$, $0.5 \%, 1 \%$ ). A series of nucleotides (AMP, ADP, ATP, CMP, CTP, GMP, GDP, GTP, UTP) was added in various concentrations to investigate their effect on the recombinant PhGn2E. Kinetic parameters were determined by using different concentrations of GlcNAc (ranging between $50 \mathrm{mM}$ and $1200 \mathrm{mM}$ ). $\mathrm{V}_{\max }, \mathrm{K}_{\mathrm{M}}$ and $\mathrm{k}_{\text {cat }}$ values were calculated by applying a non-linear regression model using Labplot data analysis software (Version 2.0.1.) (labplot.kde.org).

\subsection{Synthesis of N-Substituted Glucosamine Derivatives and Determination of PhGn2E Substrate Promiscuity}

GlcNAc analogues bearing different $N$-linked substituents were synthesized using a similar activated ester method (AES) as described previously [50]. In brief, $1 \mathrm{mmol}$ of $\mathrm{N}$-hydroxysuccinimide (NHS), $1 \mathrm{mmol}$ dicyclohexylcarbodiimide (DCC) and $1 \mathrm{mmol}$ of acid (acetic acid, propionic acid, butyric acid, hexanoic acid, octanoic acid, decanoic acid, stearic acid, benzoic acid, 2-picolinic acid, glycolic acid, thioglycolic acid, or azidoacetic acid) were dissolved in ethyl acetate $(6 \mathrm{~mL})$ and stirred overnight at room temperature. The reaction mixture was centrifuged at $14,000 \mathrm{~g}$ for $10 \mathrm{~min}$. The supernatant was added drop-wise into $4 \mathrm{~mL}$ of a glucosamine solution $(0.8 \mathrm{mmol} \mathrm{GlcN}$ in $10 \%(v / v)$ methanolic triethylamine). The resulting solution was stirred for $2 \mathrm{~h}$ at room temperature, the solvent was evaporated under reduced pressure and the resulting solid re-dissolved in $1.6 \mathrm{~mL}$ of an aqueous methanol solution $(10 \% v / v)$. All substrates showed good solubility, with the exception of $\mathrm{N}$-octadecanoylglucosamine (solubility of $8.8 \mathrm{mg} / \mathrm{mL}$ in $10 \%$ aqueous methanol at $37^{\circ} \mathrm{C}$ ). The substrate promiscuity of PhGn2E was measured using the platereader-based assay described in Section 4.5.

NMR analysis was used to evaluate enzyme-catalyzed reactions towards glucosamine, $\alpha$-methyl GlcNAc and $\beta$-methyl GlcNAc. ${ }^{1} \mathrm{H}-\mathrm{NMR}$ spectra were acquired on a $400 \mathrm{MHz}$ NMR instrument (Bruker, Bremen, Germany) using deuterium oxide as the solvent.

\subsection{Enzymatic Synthesis and Analysis of Indoxylsialosides}

Sialic acid analogues were synthesized based on a method previously reported by Cao et al. for p-nitrophenyl-linked sialosides [38]. This one-pot, four-enzyme reaction (Scheme 1, Route B) consists of the C2-epimerization of the GlcNAc derivatives, followed by an aldolase catalyzed aldol reaction to obtain C5-derivatized neuraminic acids. These derivatives were then activated using CMP-sialic acid synthetase and transferred to the acceptor substrate 5-bromo-4-chloro-3-indolyl- $\beta$-D-galactose (X-gal) by a sialic acid transferase. The expression and purification of the three latter enzymes was performed as previously described [51]. The reaction mixture consisted of $50 \mathrm{mM} \mathrm{GlcNAc}$ analogue, $2 \mathrm{mM} \mathrm{CTP}$, $2 \mathrm{mM} \mathrm{MgCl}$, $10 \mathrm{mM}$ pyruvate, $2 \mathrm{mM}$ X-gal, $50 \mathrm{mM}$ MES (pH 6.5), $3 \mu \mathrm{M}$ PhGn2E, $3 \mu \mathrm{M}$ E. coli aldolase, $3 \mu \mathrm{M}$ Neisseria meningitidis CMP-sialic acid synthetase and $5 \mu \mathrm{M}$ Photobacterium damsalae sialic acid transferase. After $16 \mathrm{~h}$ of incubation at $37^{\circ} \mathrm{C}$, samples were analyzed using reversed phase HPLC with online UV and ESI-MS detection (Shimadzu MS-2020, Tokyo, Japan). The analytes were separated 
using a HyperClone $5 \mu \mathrm{m}$ ODS column ( $250 \times 4.6 \mathrm{~mm}$, Phenomenex), with an ammonium formate eluent $(50 \mathrm{mM}, \mathrm{pH} 4.5,1 \mathrm{~mL} / \mathrm{min}$ ) mixed with increasing concentrations of acetonitrile (from $10 \%$ to $60 \%$ in the first $8 \mathrm{~min}$ ) and detected at a UV wavelength of $300 \mathrm{~nm}$. The ESI-mass detection was performed in negative ionization mode scanning an $\mathrm{m} / \mathrm{z}$ range between 300 and 1000 .

\subsection{Mechanistic NMR Studies}

${ }^{1} \mathrm{H}-\mathrm{NMR}$ spectra were recorded on a Bruker AV-400 instrument, using the residual deuterium oxide and dimethyl sulfoxide- $d_{6}$ (DMSO- $d_{6}$ ) residual solvent signals as internal standards. For studying the C-2 hydrogen/deuterium exchange, approx. $3 \mathrm{mg}$ of purified PhGn2E were dialyzed for $72 \mathrm{~h}$ against deionized water and subsequently lyophilized. The dried enzyme was re-dissolved in $600 \mu \mathrm{L}$ of deuterium oxide containing $100 \mathrm{mM}$ GlcNAc and incubated at $37{ }^{\circ} \mathrm{C}$ overnight. Spectra were recorded without any further sample treatment. For the hydrogen/deuterium exchange analysis of the anomeric alcohol, $3 \mathrm{mg}$ of lyophilized epimerase was dissolved $300 \mu \mathrm{L}$ of deuterium oxide containing $20 \mathrm{mM} \mathrm{GlcNAc}$, and incubated at $37^{\circ} \mathrm{C}$ for $15 \mathrm{~min}$. After the solvent was evaporated, ${ }^{1} \mathrm{H}-\mathrm{NMR}$ spectra were collected in deuterated DMSO- $d_{6}$. Negative control experiments were performed by inactivating the lyophilized epimerase with methanol.

\subsection{Activity Screening Using PhGn2E Mutants}

Complementary oligonucleotide primers containing the desired mutation were used to generate PhGn2E mutant genes (Supplementary Table S2) according to the QuikChange overlap PCR Site-Directed Mutagenesis protocol (Stratagene). Verified plasmids containing the desired mutation in the target gene were transformed into E. coli BL21 (DE3) competent cells. PhGn2E mutant proteins were expressed and purified as described in Section 4.4. Activity tests were performed in $40 \mu \mathrm{L}$ reaction mixtures containing $50 \mathrm{mM}$ GlcNAc, $3 \mu \mathrm{M}$ PhGn2E mutant or wild type in citrate/phosphate buffer (50 mM, pH 8.0), and were incubated at $37^{\circ} \mathrm{C}$ for $4 \mathrm{~h}$. Negative controls contained heat-inactivated $\mathrm{PhGn} 2 \mathrm{E}\left(95^{\circ} \mathrm{C}\right.$ for $15 \mathrm{~min}$ ) instead of the native enzyme. The reaction mixture was then analyzed using the platereader-based assay described in Section 4.5.

\section{Conclusions}

Our study describes the biochemical characterization and the substrate promiscuity of a previously unstudied GlcNAc 2-epimerase from Pedobacter heparinus. For the first time, experimental evidence of the proposed deprotonation/reprotonation mechanism for this type of enzyme could be demonstrated. This was achieved in NMR experiments by observing the hydrogen/deuterium exchange at C-2 and in the anomeric alcohol of the substrates. An activity study of PhGn2E mutant enzymes suggests that the proton abstraction/addition is catalyzed by Arg63 and Glu314. These residues do also appear in the active site of the closely homologous mammalian GlcNAc 2-epimerase, indicating that mammalian GlcNAc 2-epimerases also employ a deprotonation/reprotonation mechanism for epimerization. These biochemical and mechanistical findings in PhGn2E may help to gain a deeper understanding of the metabolism of GlcNAc and consequently sialic acids in living cells. Crystallization studies of the PhGn2E haloenzyme are a part of our current research program.

Supplementary Materials: The following are available online at www.mdpi.com/2073-4344/6/12/212/s1. Figure S1: Amino acids sequence alignment of GlcNAc 2-epimerases from Bos taurus, Homo sapiens, Mus musculus, Sus scrofa, Anabaena sp. CH1 and Pedobacter heparinus. Figures S2 and S3: NMR characterization of GlcNAc analogues. Figures S4-S6: MS analysis of the Neu5Ac $\alpha 2-6 \mathrm{Gal} \beta \mathrm{X}$ analogues. Figure S7: Thermo stability analysis of PhGn2E. Figure S8: The effect of detergents and denaturants on PhGn2E. Figure S9: Effects of nucleotides on PhGn2E. Figure S10: possible enzymatic epimerization mechanisms. Figure S11: Structural overlay of porcine Gn2E with modeled PhGn2E. Table S1: MALDI-TOF MS analysis of purified PhGn2E. Table S2: Primer sequences for generating mutant PhGn2E variants.

Acknowledgments: This work was supported in part by the Natural Science Foundation of China (grant numbers 31471703, A0201300537 and 31671854 to J.V. and L.L.), and the 100 Foreign Talents Plan (grant number JSB2014012 to J.V.). The authors would like to thank Louis Conway (GGBRC, Nanjing) for language editing of this manuscript. 
Author Contributions: S.-Y.W. designed and performed experiments, analyzed the data and drafted the manuscript. P.L. designed NMR experiment, analyzed the NMR data and assisted in the manuscript preparation. A.-M.L. performed the NMR experiment. X.-C.D. cloned PhGn2E. H.-Y.M. performed mass spectrometric analysis. J.V. and L.L. conceived the project, designed experiments, and organized and finalized the manuscript.

Conflicts of Interest: The authors declare no conflict of interest.

\section{References}

1. Inoue, S.; Kitajima, K. KDN (deaminated neuraminic acid): Dreamful past and exciting future of the newest member of the sialic acid family. Glycoconj. J. 2006, 23, 277-290. [CrossRef] [PubMed]

2. Schauer, R. Chemistry, metabolism, and biological functions of sialic acids. Adv. Carbohydr. Chem. Biochem. 1982, 40, 131-234. [PubMed]

3. Tzanakakis, G.N.; Syrokou, A.; Kanakis, I.; Karamanos, N.K. Determination and distribution of N-acetyl-and $\mathrm{N}$-glycolylneuraminic acids in culture media and cell-associated glycoconjugates from human malignant mesothelioma and adenocarcinoma cells. Biomed. Chromatogr. 2006, 20, 434-439. [CrossRef] [PubMed]

4. Devine, P.L.; Clark, B.A.; Birrell, G.W.; Layton, G.T.; Ward, B.G.; Alewood, P.F.; McKenzie, I.F.C. The breast tumor-associated epitope defined by monoclonal-antibody $3 \mathrm{E} 1.2$ is an O-linked mucin carbohydrate containing N-glycolilneuraminic acid. Cancer Res. 1991, 51, 5826-5836. [PubMed]

5. Hedlund, M.; Tangvoranuntakul, P.; Takematsu, H.; Long, J.M.; Housley, G.D.; Kozutsumi, Y.; Suzuki, A.; Wynshaw-Boris, A.; Ryan, A.F.; Gallo, R.L.; et al. N-glycolylneuraminic acid deficiency in mice: Implications for human biology and evolution. Mol. Cell. Biol. 2007, 27, 4340-4346. [CrossRef] [PubMed]

6. Nasonkin, I.O.; Koliatsos, V.E. Nonhuman sialic acid Neu5Gc is very low in human embryonic stem cell-derived neural precursors differentiated with B27/N2 and noggin: Implications for transplantation. Exp. Neurol. 2006, 201, 525-529. [CrossRef] [PubMed]

7. Du, J.; Meledeo, M.A.; Wang, Z.Y.; Khanna, H.S.; Paruchuri, V.D.P.; Yarema, K.J. Metabolic glycoengineering: Sialic acid and beyond. Glycobiology 2009, 19, 1382-1401. [CrossRef] [PubMed]

8. Keppler, O.T.; Horstkorte, R.; Pawlita, M.; Schmidts, C.; Reutter, W. Biochemical engineering of the N-acyl side chain of sialic acid: Biological implications. Glycobiology 2001, 11, 11R-18R. [CrossRef] [PubMed]

9. Lawrence, S.M.; Huddleston, K.A.; Pitts, L.R.; Nguyen, N.; Lee, Y.C.; Vann, W.F.; Coleman, T.A.; Betenbaugh, M.J. Cloning and expression of the human $N$-acetylneuraminic acid phosphate synthase gene with 2-keto-3-deoxy-D-glycero-D-galacto-nononic acid biosynthetic ability. J. Biol. Chem. 2000, 275, 17869-17877. [CrossRef] [PubMed]

10. Stasche, R.; Hinderlich, S.; Weise, C.; Effertz, K.; Lucka, L.; Moormann, P.; Reutter, W. A bifunctional enzyme catalyzes the first two steps in $N$-acetylneuraminic acid biosynthesis of rat liver-Molecular cloning and functional expression of UDP- $N$-acetyl-glucosamine 2-epimerase/ $N$-acetylmannosamine kinase. J. Biol. Chem. 1997, 272, 24319-24324. [CrossRef] [PubMed]

11. Blick, T.J.; Tiong, T.; Sahasrabudhe, A.; Varghese, J.N.; Colman, P.M.; Hart, G.J.; Bethell, R.C.; McKimmBreschkin, J.L. Generation and characterization of an influenza virus neuraminidase variant with decreased sensitivity to the neuraminidase-specific inhibitor 4-guanidino-Neu5Ac2en. Virology 1995, 214, 475-484. [CrossRef] [PubMed]

12. Lawrence, S.M.; Huddleston, K.A.; Tomiya, N.; Nguyen, N.; Lee, Y.C.; Vann, W.F.; Coleman, T.A.; Betenbaugh, M.J. Cloning and expression of human sialic acid pathway genes to generate CMP-sialic acids in insect cells. Glycoconj. J. 2001, 18, 205-213. [CrossRef] [PubMed]

13. Varki, A. Radioactive tracer techniques in the sequencing of glycoprotein oligosaccharides. FASEB J. 1991, 5 , 226-235. [PubMed]

14. Luchansky, S.J.; Yarema, K.J.; Takahashi, S.; Bertozzi, C.R. GlcNAc 2-epimerase can serve a catabolic role in sialic acid metabolism. J. Biol. Chem. 2003, 278, 8035-8042. [CrossRef] [PubMed]

15. Ghosh, S.; Roseman, S. The sialic acids. V. N-acyl-D-glucosamine 2-epimerase. J. Biol. Chem. 1965, 240, 1531-1536. [PubMed]

16. Takahashi, S.; Hori, K.; Ogasawara, H.; Hiwatashi, K.; Sugiyama, T. Effects of Nucleotides on the interaction of renin with G1cNAc 2-epimerase (Renin binding protein, RnBP). J. Biochem. 2006, 140, 725-730. [CrossRef] [PubMed] 
17. Takahashi, S.; Ogasawara, H.; Takahashi, K.; Hori, K.; Saito, K.; Mori, K. Identification of a domain conferring nucleotide binding to the $N$-acetyl-D-glucosamine 2-epimerase (renin binding protein). J. Biochem. 2002, 131, 605-610. [CrossRef] [PubMed]

18. Itoh, T.; Mikami, B.; Maru, I.; Ohta, Y.; Hashimoto, W.; Murata, K. Crystal structure of N-acyl-D-glucosamine 2-epimerase from porcine kidney at 2.0 angstrom resolution. J. Mol. Biol. 2000, 303, 733-744. [CrossRef] [PubMed]

19. Klermund, L.; Groher, A.; Castiglione, K. New N-acyl-D-glucosamine 2-epimerases from cyanobacteria with high activity in the absence of ATP and low inhibition by pyruvate. J. Biotechnol. 2013, 168, $256-263$. [CrossRef] [PubMed]

20. Lee, Y.C.; Chien, H.C.R.; Hsu, W.H. Production of N-acetyl-D-neuraminic acid by recombinant whole cells expressing Anabaena sp. CH1N-acetyl-D-glucosamine 2-epimerase and Escherichia coli N-acetyl-D-neuraminic acid lyase. J. Biotechnol. 2007, 129, 453-460. [CrossRef] [PubMed]

21. Klermund, L.; Riederer, A.; Groher, A.; Castiglione, K. High-level soluble expression of a bacterial $\mathrm{N}$-acyl-D-glucosamine 2-epimerase in recombinant Escherichia coli. Protein Expr. Purif. 2015, 111, 36-41. [CrossRef] [PubMed]

22. Sola-Carvajal, A.; Sanchez-Carron, G.; Garcia-Garcia, M.I.; Garcia-Carmona, F.; Sanchez-Ferrer, A. Properties of BoAGE2, a second N-acetyl-D-glucosamine 2-epimerase from Bacteroides ovatus ATCC 8483. Biochimie 2012, 94, 222-230. [CrossRef] [PubMed]

23. Liao, H.F.; Kao, C.H.; Lin, W.D.; Hsiao, N.W.; Hsu, W.H.; Lee, Y.C. N-Acetyl-D-glucosamine 2-epimerase from Anabaena sp. CH1 contains a novel ATP-binding site required for catalytic activity. Process Biochem. 2012, 47, 948-952. [CrossRef]

24. Samuel, J.; Tanner, M.E. Mechanistic aspects of enzymatic carbohydrate epimerization. Nat. Prod. Rep. 2002, 19, 261-277. [CrossRef] [PubMed]

25. Lee, Y.C.; Wu, H.M.; Chang, Y.N.; Wang, W.C.; Hsu, W.H. The central cavity from the (alpha/alpha)(6) barrel structure of Anabaena sp. CH1N-acetyl-D-glucosamine 2-epimerase contains two key histidine residues for reversible conversion. J. Mol. Biol. 2007, 367, 895-908. [CrossRef] [PubMed]

26. Ulrich, E.L.; Akutsu, H.; Doreleijers, J.F.; Harano, Y.; Ioannidis, Y.E.; Lin, J.; Livny, M.; Mading, S.; Maziuk, D.; Miller, Z. BioMagResBank. Nucleic Acids Res. 2008, 36, D402-D408. [CrossRef] [PubMed]

27. Tabata, K.; Koizumi, S.; Endo, T.; Ozaki, A. Production of N-acetyl-D-neuraminic acid by coupling bacteria expressing $N$-acetyl-D-glucosamine 2-epimerase and $N$-acetyl-D-neuraminic acid synthetase. Enzym. Microb. Technol. 2002, 30, 327-333. [CrossRef]

28. Moncla, B.; Braham, P.; Hillier, S. Sialidase (neuraminidase) activity among gram-negative anaerobic and capnophilic bacteria. J. Clin. Microbiol. 1990, 28, 422-425. [PubMed]

29. Maru, I.; Ohta, Y.; Murata, K.; Tsukada, Y. Molecular cloning and identification of N-acyl-D-glucosamine 2-epimerase from porcine kidney as a renin-binding protein. J. Biol. Chem. 1996, 271, 16294-16299. [CrossRef] [PubMed]

30. Takahashi, S.; Hori, K.; Takahashi, K.; Ogasawara, H.; Tomatsu, M.; Saito, K. Effects of nucleotides on $\mathrm{N}$-acetyl-D-glucosamine 2-epimerases (renin-binding proteins): Comparative biochemical studies. J. Biochem. 2001, 130, 815-821. [CrossRef] [PubMed]

31. Chou, W.K.; Hinderlich, S.; Reutter, W.; Tanner, M.E. Sialic acid biosynthesis: Stereochemistry and mechanism of the reaction catalyzed by the mammalian UDP-N-acetylglucosamine 2-epimerase. J. Am. Chem. Soc. 2003, 125, 2455-2461. [CrossRef] [PubMed]

32. Wratil, P.R.; Rigol, S.; Solecka, B.; Kohla, G.; Kannicht, C.; Reutter, W.; Giannis, A.; Nguyen, L.D. A novel approach to decrease sialic acid expression in cells by a C-3-modified $\mathrm{N}$-acetylmannosamine. J. Biol. Chem. 2014, 289, 32056-32063. [CrossRef] [PubMed]

33. Mahal, L.K.; Yarema, K.J.; Bertozzi, C.R. Engineering chemical reactivity on cell surfaces through oligosaccharide biosynthesis. Science 1997, 276, 1125-1128. [CrossRef] [PubMed]

34. Schwartz, E.L.; Hadfield, A.F.; Brown, A.E.; Sartorelli, A.C. Modification of sialic acid metabolism of murine erythroleukemia cells by analogs of N-acetylmannosamine. Biochim. Biophys. Acta 1983, 762, 489-497. [CrossRef] 
35. Aich, U.; Meledeo, M.A.; Sampathkumar, S.G.; Fu, J.; Jones, M.B.; Weier, C.A.; Chung, S.Y.; Tang, B.C.; Yang, M.; Hanes, J.; et al. Development of delivery methods for carbohydrate-based drugs: Controlled release of biologically-active short chain fatty acid-hexosamine analogs. Glycoconj. J. 2010, 27, 445-459. [CrossRef] [PubMed]

36. Kim, E.J.; Sampathkumar, S.G.; Jones, M.B.; Rhee, J.K.; Baskaran, G.; Goon, S.; Yarema, K.J. Characterization of the metabolic flux and apoptotic effects of $O$-hydroxyl- and $N$-acyl-modified $N$-acetylmannosamine analogs in Jurkat cells. J. Biol. Chem. 2004, 279, 18342-18352. [CrossRef] [PubMed]

37. Laborda, P.; Wang, S.-Y.; Voglmeir, J. Influenza Neuraminidase Inhibitors: Synthetic Approaches, Derivatives and Biological Activity. Molecules 2016, 21, 1513. [CrossRef] [PubMed]

38. Cao, H.Z.; Li, Y.H.; Lau, K.; Muthana, S.; Yu, H.; Cheng, J.S.; Chokhawala, H.A.; Sugiarto, G.; Zhang, L.; Chen, $X$. Sialidase substrate specificity studies using chemoenzymatically synthesized sialosides containing C5-modified sialic acids. Org. Biomol. Chem. 2009, 7, 5137-5145. [CrossRef] [PubMed]

39. Yu, H.; Karpel, R.; Chen, X. Chemoenzymatic synthesis of CMP-sialic acid derivatives by a one-pot two-enzyme system: Comparison of substrate flexibility of three microbial CMP-sialic acid synthetases. Bioorg. Med. Chem. 2004, 12, 6427-6435. [CrossRef] [PubMed]

40. Jacobs, C.L.; Goon, S.; Yarema, K.J.; Hinderlich, S.; Hang, H.C.; Chai, D.H.; Bertozzi, C.R. Substrate specificity of the sialic acid biosynthetic pathway. Biochemistry 2001, 40, 12864-12874. [CrossRef] [PubMed]

41. Sampathkumar, S.G.; Li, A.V.; Yarema, K.J. Synthesis of non-natural ManNAc analogs for the expression of thiols on cell-surface sialic acids. Nat. Protoc. 2006, 1, 2377-2385. [CrossRef] [PubMed]

42. Ress, D.K.; Linhardt, R.J. Sialic acid donors: Chemical synthesis and glycosylation. Curr. Org. Synth. 2004, 1, 31-46. [CrossRef]

43. De Meo, C.; Priyadarshani, U. C-5 modifications in $\mathrm{N}$-acetyl-neuraminic acid: Scope and limitations. Carbohydr. Res. 2008, 343, 1540-1552. [CrossRef] [PubMed]

44. Keppler, O.T.; Herrmann, M.; von der Lieth, C.W.; Stehling, P.; Reutter, W.; Pawlita, M. Elongation of the $\mathrm{N}$-acyl side chain of sialic acids in MDCK II cells inhibits influenza A virus infection. Biochem. Biophys. Res. Commun. 1998, 253, 437-442. [CrossRef] [PubMed]

45. Lundgren, B.R.; Boddy, C.N. Sialic acid and N-acyl sialic acid analog production by fermentation of metabolically and genetically engineered Escherichia coli. Org. Biomol. Chem. 2007, 5, 1903-1909. [CrossRef] [PubMed]

46. Yu, H.; Chokhawala, H.A.; Huang, S.; Chen, X. One-pot three-enzyme chemoenzymatic approach to the synthesis of sialosides containing natural and non-natural functionalities. Nat. Protoc. 2006, 1, 2485-2492. [CrossRef] [PubMed]

47. Morgan, P.M.; Sala, R.F.; Tanner, M.E. Eliminations in the reactions catalyzed by UDP-N-acetylglucosamine 2-epimerase. J. Am. Chem. Soc. 1997, 119, 10269-10277. [CrossRef]

48. Mahuku, G.S. A simple extraction method suitable for PCR-based analysis of plant, fungal, and bacterial DNA. Plant Mol. Biol. Rep. 2004, 22, 71-81. [CrossRef]

49. Yu, H.; Huang, S.; Chokhawala, H.; Sun, M.; Zheng, H.; Chen, X. Highly efficient chemoenzymatic synthesis of naturally occurring and non-natural alpha-2,6-linked sialosides: A P. damsela alpha-2,6-sialyltransferase with extremely flexible donor-substrate specificity. Angew. Chem.-Int. Ed. 2006, 45, 3938-3944. [CrossRef] [PubMed]

50. Yao, H.L.; Conway, L.P.; Wang, M.M.; Huang, K.; Liu, L.; Voglmeir, J. Quantification of sialic acids in red meat by UPLC-FLD using indoxylsialosides as internal standards. Glycoconj. J. 2016, 33, 219-226. [CrossRef] [PubMed]

51. Laver, W.G. Purification, N-terminal amino acid analysis, and disruption of an influenza virus. Virology 1961, 14, 499-502. [CrossRef]

(C) 2016 by the authors; licensee MDPI, Basel, Switzerland. This article is an open access article distributed under the terms and conditions of the Creative Commons Attribution (CC-BY) license (http:/ / creativecommons.org/licenses/by/4.0/). 